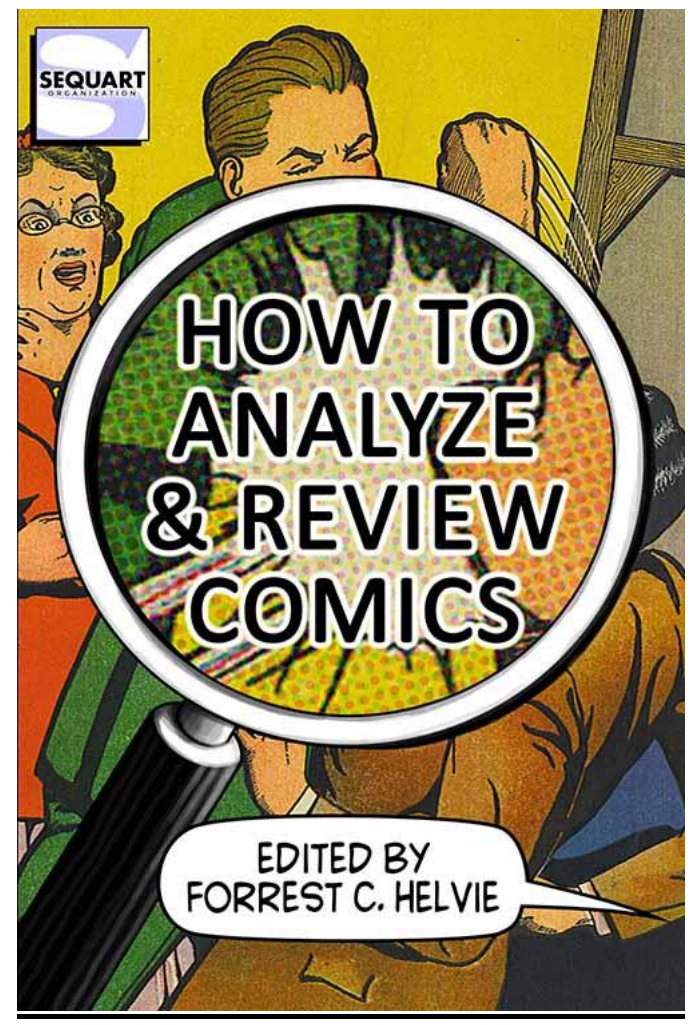

\title{
Um guia para críticos de histórias em quadrinhos
}

\section{A guide for comics critics}

\author{
d. \\ 10.11606/2316-9877.2021.v9i2.194057 \\ Nobu Chinen ${ }^{1}$ \\ Observatório de Histórias em Quadrinhos da ECA-USP
}

O que faz uma história em quadrinhos ser melhor do que outra? Que atributos e características devem ser levados em conta ao se analisar uma tira, uma série, um gibi ou uma graphic nove/ para classificar esse material como sendo bom ou ruim? Por que alguns títulos são celebrados como obras de arte pelos estudiosos enquanto muitos outros nem são mencionados ou sequer lembrados?

Tais questões têm se tornado cada vez mais relevantes diante da multiplicação de canais dedicados aos quadrinhos que abrem espaço para comentários e críticas às produções feitas nessa linguagem. Diferentemente da

\footnotetext{
1 Doutor em Ciências da Comunicação pela Escola de Comunicações e Artes da Universidade de São Paulo. Email: nobuchinen@uol.com.br. (D) https://orcid.org/0000-0003-3632-2354
} 
literatura e do cinema, que há muitas décadas contavam com críticas publicadas nos principais jornais e revistas do país, quando não em publicações e cadernos exclusivamente voltados a esses campos, até meados da década de 1980, matérias e reportagens sobre séries e personagens de quadrinhos eram raras e irregulares, com destaque para o trabalho de pioneiros como Alvaro de Moya, Moacy Cirne, Sérgio Augusto e Orlando Fassoni. Foi somente com o advento dos gibis para o público adulto e a consolidação do mercado das chamadas graphic novels, que a imprensa, de modo geral, passou a publicar colunas para noticiar sobre os lançamentos do setor, a ponto de, no início dos anos 1990, os quatro principais diários da cidade de São Paulo manterem uma página inteira semanal sobre quadrinhos. Com o surgimento da internet e sua popularização, no começo do século XXI, houve a proliferação de blogs e sites especializados em quadrinhos o que aumentou ainda mais a sua visibilidade como tema merecedor de comentários e resenhas. Mais recentemente, as redes sociais propiciaram a disseminação de podcasts e canais pessoais no YouTube, e a crítica de quadrinhos passou a ser exercida de forma indistinta, seja por fãs que expressam suas opiniões e predileções sem se ater a nenhum critério claro, a acadêmicos que elaboram ensaios e resenhas mais aprofundadas seguindo as mais variadas linhas de pesquisa, desde a semiológica e artística à histórica e social.

Ainda que se tente ser imparcial, muito do que levamos em consideração ao analisar uma história em quadrinhos tem um forte componente de subjetividade: afinal, é fácil se deixar levar pelo gosto pessoal, pelo momento (e eu acrescentaria experiência) de vida, até por certos "preconceitos" em relação a determinados gêneros, autores e temas que, por algum motivo, atraem menos a nossa atenção do que outros.

O ideal é que um crítico faça uma análise isenta e o mais desapaixonada possível e para tanto precisa estabelecer alguns parâmetros que permitam estabelecer o nível de qualidade de uma história em quadrinhos em relação às outras. Nesse aspecto, o livro How to analyze \& review comics, editado por Forrest C. Helvie, e lançado em 2021 pela Sequart, pode ser uma ferramenta bastante útil. O livro, que tem como subtítulo A Handbook on Comics Criticism (Manual de Crítica de Quadrinhos), é dividido em cinco seções: Getting down to basics: Line Art, Inking, Colors and Lettering; Navigating Comics; The History and Development of Comics: a Primer; Concerns of Critics; e Beyond the Printed Page. 
Cada seção é formada por diferentes textos que somam 22 capítulos, de 27 autores. Os capítulos, por sinal, são bem curtos: os mais extensos têm 10 páginas e a maioria, entre quatro e cinco. Dessa forma, nenhum deles seria aprovado para publicação em revistas acadêmicas, pois muitas delas exigem um número mínimo de páginas. No entanto, embora sucintos, os textos são diretos, claros e objetivos quanto ao que se propõem a apresentar ou defender.

O livro parte de conceitos mais óbvios ou mais visíveis a qualquer leitor e segue uma linha evolutiva que compreende a linguagem dos quadrinhos, os formatos, os gêneros, as possibilidades analíticas e abordagens mais complexas com comentários sobre a própria função da crítica dos quadrinhos. Seria exaustivo comentar ou resumir o conteúdo de cada um dos capítulos que, como já informado, são por si enxutos, portanto, nesta resenha farei apenas uma breve descrição das seções, com destaque para um ou outro capítulo.

Os capítulos da primeira seção tratam individualmente dos elementos básicos que compõem a linguagem dos quadrinhos: os desenhos, os textos, os balões, o letreiramento etc.

Na segunda seção, os textos passam a abordar o conjunto, as relações entre os quadrinhos e a composição da página como um todo. Ao ler o capítulo "Camera Angles, Panel Framing and Reader Perspective", de El Anderson, que trata do uso de planos, ângulos e enquadramentos, nota-se a influência do tipo de análise semiológica recorrente nos anos 1960-70, muito baseada nos conceitos e termos emprestados da cinematografia. É impossível não se lembrar da famosa análise da página de estreia de Steve Canyon, personagem de Milton Caniff, que Umberto Eco fez há cerca de 60 anos, publicada no livro Apocalípticos e Integrados.

A terceira seção leva em conta os contextos históricos em que os quadrinhos se desenvolveram. Um dos capítulos discorre sobre os diferentes formatos nos quais os quadrinhos foram e são publicados. Em "Comic Genres: an Historical Overview", Philip Smith tenta estabelecer uma divisão por gêneros, com um resultado controverso, uma vez que, como o próprio autor justifica, está centrada na produção norte-americana. Ele também admite que é difícil encaixar algumas produções em um ou outro gênero, fato que pessoas do meio estão cansadas de saber.

Os capítulos da quarta seção abordam pontos específicos da crítica dos quadrinhos. No primeiro deles, "Every Word Counts: Long-Form vs. Short-Form 
Critiques", Christine Atchinson comenta sobre tipos de análises das mais superficiais e curtas às mais profundas e, por isso, mais extensas. Aqui entra uma discussão muito atual que confronta textos informativos e artigos acadêmicos que têm propósitos diferentes e são dirigidos a públicos distintos. Já no capítulo Comics and Context: The Questions That Must Be Asked, de A. Davis Lewis, o autor propõe seis perguntas que todo crítico ou resenhista deve se fazer ao analisar uma história em quadrinhos. É uma proposta interessante como ponto de partida. Buscar as respostas pode se revelar uma tarefa desafiadora, uma vez que elas nem sempre são evidentes como poderíamos imaginar. Os demais capítulos levantam questões de gênero e de representatividade, abordagens cada vez mais comuns nos estudos críticos dos quadrinhos.

Na última seção, os dois capítulos que a compõem comentam sobre a internet tanto como mídia para publicação de quadrinhos, os webcomics, como plataforma para as críticas, incluindo formatos como os podcasts sobre quadrinhos que, aliás, têm proliferado em grande quantidade no Brasil

Grande parte dos autores de How to analyze... pertence ao meio acadêmico, com vários deles sendo detentores de $\mathrm{PhD}$, título equivalente ao de doutor no Brasil. Quase todos são norte-americano, o que explica a predominância de citações a estudiosos conterrâneos com exceção das menções ao espanhol Sergio Garcia e ao francês Thierry Groensteen. Também é notável como Will Eisner e Scott McCloud se mantêm como as principais referências entre os trabalhos teóricos citados, ainda mais se considerarmos que seus livros já têm mais de 30 anos.

How to analyze... também traz breves entrevistas com profissionais da área, entre desenhistas, roteiristas e letreiristas. As informações de quem cria e produz quadrinhos são fundamentais para se compreender melhor a realidade que envolve essa linguagem e servem de complemento e de contraste aos ensaios que formam os capítulos. A propósito, um dos depoimentos mais sensatos é de Becky Cloonan que aconselha: "(como crítico) você deve ser capaz de reconhecer o valor contido em alguma obra que talvez, particularmente, não aprecie e o oposto também é verdadeiro, ou seja, é importante saber criticar um quadrinho mesmo que você goste dele"2. Por outro lado, não devemos nos pautar por critérios absolutamente

\footnotetext{
2 You have to be able to recognize the value in something that you might not personally like, and equally and oppositely true, it's important to be able to enjoy something and to be able to critique it at same time.
} 
técnicos. Isso seria impossível, em se tratando de obras de cunho artístico, mesmo aquelas de caráter eminentemente comercial, e cada análise estará inevitavelmente impregnada de uma visão particular e pessoal de cada crítico.

A Sequart se define como uma organização dedicada ao estudo da cultura pop e foi fundada em 1996 por Julian Darius. Embora o nome Sequart seja uma sigla de sequential art, ou arte sequencial em português, uma das definições utilizadas para histórias em quadrinhos, ela também publica livros sobre outras mídias da cultura pop com obras dedicadas a filmes de ficção científica como Star Wars e Blade Runner. A Sequart também produz documentários sobre quadrinhos e um deles, Diagram for delinquents, aborda o legado do doutor Fredric Wertham, psiquiatra considerado o inimigo número um dos quadrinhos e autor do livro Seduction of the Innocent (SOTI). O filme traz depoimentos de Carol Tilley, pesquisadora que denunciou fraudes nas pesquisas relatadas em SOTI, e James E. Reibman, biógrafo de Wertham, cada um em campos opostos, fala sobre o polêmico doutor, sua obra e suas motivações.

A utilidade de How to analyze... não se restringe a proporcionar parâmetros confiáveis para quem pretende redigir críticas e resenhas. O livro oferece igualmente subsídios que ajudam no julgamento ou na comparação de diferentes obras.

Há vários anos, venho atuando como jurado em algumas das mais importantes premiações dos quadrinhos no Brasil. Isso implica ler uma grande quantidade de gibis dos mais diferentes gêneros e estilos para elaborar uma lista daqueles que considero os melhores. Aliás, foi no meio do processo de seleção de obras em uma dessas premiações que descobri o livro e me interessei em lê-lo. Além disso, por causa de participações relativamente frequentes em bancas de TCCs, e de trabalhos de pós-graduação, procuro ler, e em alguns casos reler, na medida do possível, os quadrinhos que se constituem em objetos de estudo desses trabalhos, sempre com um olhar mais crítico.

Obviamente, isso não significa que ler somente How to analyze \& review comics habilite uma pessoa a ser um crítico de quadrinhos. Ele é um bom guia, mas não substitui o domínio de uma bibliografia mínima a respeito de histórias em quadrinhos nos mais variados campos de estudo, começando com os já citados Eisner, McCloud e Groensteen, mas que deve incluir Daniele Barbieri, Moacy Cirne, 
Alvaro de Moya, Sonia Luyten, Barbara Postema, Waldomiro Vergueiro, Paulo Ramos e Roberto Elísio dos Santos, apenas para citar alguns.

Porém, mais importante que ter um bom repertório de obras teóricas, é ler muitos quadrinhos. Quanto maior a quantidade e a diversidade, melhor. Ler gibis sem preconceitos em relação a nenhum gênero ou autor, mas também sem fanatismo nem condescendência. É claro que um fã pode se tornar um bom crítico de quadrinhos, mas é preciso tomar cuidado para não deixar que predileções pessoais contaminem e prejudiquem a capacidade de julgamento e que o texto resultante dessa capacidade sirva como uma luz que oriente o leitor no longo e incerto caminho que leva aos bons gibis.

\section{Referências}

BARBIERI, Daniele. As linguagens dos quadrinhos. São Paulo: Peirópolis, 2017.

ECO, Umberto. Apocalípticos e Integrados. $4^{a}$ ed., São Paulo: Ed. Perspectiva, 1976.

EISNER, Will. Quadrinhos e Arte Sequencial. 3ª edição. São Paulo: Martins Fontes, 1999.

GROENSTEEN, Thierry. O sistema dos quadrinhos. Nova Iguaçu: Marsupial, 2015.

HELVIE, Forrest C. (ed.). How to analyze \& review comics. Edwardsville: Sequart, 2021.

MCCLOUD, Scott. Desvendando os Quadrinhos. 2ª ed., São Paulo: M. Books, 2005.

SÁNCHEZ, Sergio Garcia. Sinfonía Gráfica. Barcelona: Glénat, 2000. 